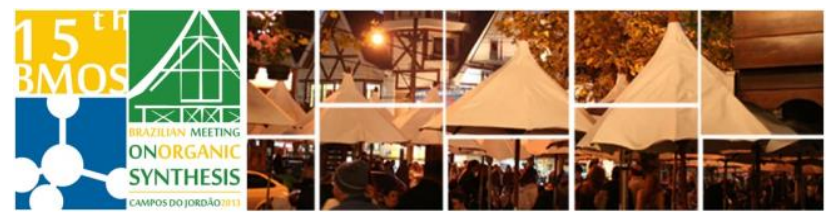

\title{
Synthesis of Isoxazolic analogues derivatives of Grandisin and Veraguensin neolignans with anti-leishmania and anti- trypanosomal activities
}

\author{
Ozildéia Soares"; Gabriela R. Hurtado'; Luiz H. Viana'; Sérgio de Albuquerque ${ }^{2}$; \\ Adriano C. M. Baroni ${ }^{{ }^{*}}$. \\ ${ }^{1}$ Laboratory of Pharmaceutical Chemistry, Center of Biological Sciences and Health, Federal University of \\ Mato Grosso do Sul, The University City s/n, Campo Grande-MS, Brazil. ${ }^{2}$ Faculty of Pharmaceutical \\ Sciences of Ribeirão Preto, University of São Paulo, Av. Coffee s/n, Ribeirão Preto-SP, Brazil. \\ *adriano.baroni@ufms.br
}

Keywords: bioisosterism; isoxazolic analogues; 1,3-dipolar cycloaddition reactions.

\section{INTRODUCTION}

The search for new biologically active compounds and, consequently, with possible use in the treatment of various diseases has been increasing in recent decades. In this study we used the bioisosterism as molecular modification strategy of the neoliganans grandisin and veraguensina what are the natural compounds with biological activity against neglected diseases. The isoxazolic heterocyclic ring was chosen as substituent of the tetrahidrofuranic rings found in these neolignans. In order to obtain more potent compounds with fewer side effects and better physicochemical characteristics, in this study were synthesized 12 isoxazolic analogues, these were sent for antileishmania and anti-trypanosomal biological activity testing, which provided us important informations about the structure-activity relationship.

\section{RESULTS AND DISCUSSION}

The first step of our work was based on the preparation of chloro oximes, from aldehydes type 1, reacted with $\mathrm{NH}_{2} \mathrm{OH}$. $\mathrm{HCl}$, for the formation of oximes type 2, oximes have seen further reaction with added NCS, in providing the chloro oximes $\mathbf{3 A - C}$. The next step was the formation of terminal acetylenes, for it left a reaction bromation, using NBS to generate bromides 5 . The reaction of the type Sonogashira cross coupling between the brominated 5 compounds and acetylene 2-methyl-3butyn-2-ol provided the acetylenic alcohols 6, that after elimination reaction type Retrofavorski, generated the terminal acetylenes 7a-d. The isoxazolic analogues were synthesized from Huisgen 1,3-dipolar cycloaddition type reactions between chloro oximes and terminal acetylenes as starting materials. Among the various methodologies tested the reaction system $\mathrm{CuSO}_{4} .5 \mathrm{H}_{2} \mathrm{O} /$ Sodium Ascorbate / $\mathrm{KHCO}_{3}$ in $\mathrm{CH}_{2} \mathrm{Cl}_{2} / \mathrm{THF}$ was one that showed the best results, 12 isoxazolic analogues 819 were synthesized by means of this system in good yields (Figure 1).

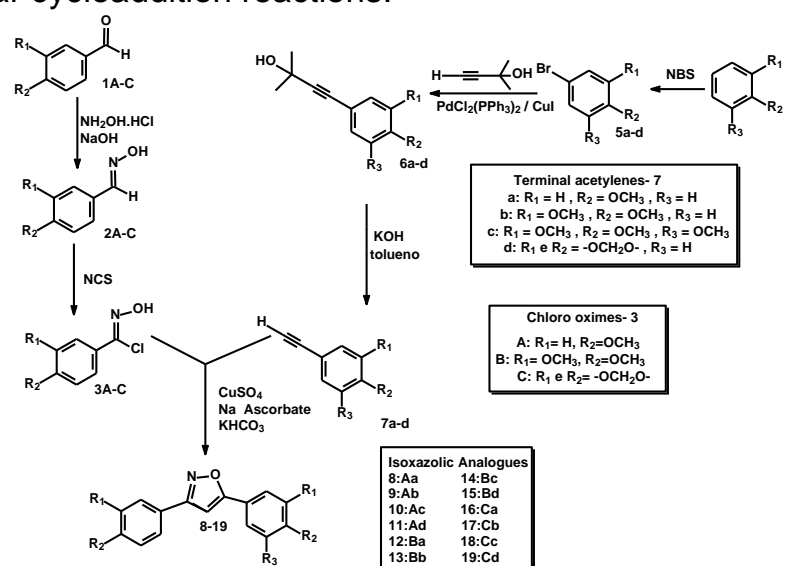

Figure 1. Synthetic route for obtaining 12 isoxazolic analogues.

The 12 compounds synthesized were sent for antileishmania and anti-trypanosomal biological activity testing, and the best results obtained between isoxazolic analogues 8-19 are shown in table 1.

Table 1. Best results for anti-leishmania and antitrypanosomal biological activity testing.

\begin{tabular}{|c|c|c|c|c|c|}
\hline *17 & ${ }^{*} 18$ & $* 10$ & ${ }^{* *} 15$ & ${ }^{\star \star} 8$ & ${ }^{*} 11$ \\
\hline $1,22 \mu \mathrm{M}$ & $2,13 \mu \mathrm{M}$ & 171,4 & $183 \mu \mathrm{M}$ & $213 \mu \mathrm{M}$ & $329 \mu \mathrm{M}$ \\
\hline
\end{tabular}

\section{CONCLUSION}

The results obtained in the synthesis and biological activity testing of 12 isoxazolic compounds were satisfactory. The compounds 17 and 18 have potential as novel drug candidates against these diseases.

\section{ACKNOWLEDGEMENTS}

CNPq, CAPES, FUNDECT-MS, PROPP/UFMS.

\section{REFERENCES}

${ }^{1}$ Vieira, André A.; Bryk, F.; Conte, G.; Bortoluzzi, A.J.; Gallardo, H. Tetrahedron Letters. 2009, 50, 905-908.

${ }^{2}$ Sonogashira, K. J. Organometalic. Chem. 2002, 653, 46. 